portrayal of unhealthy food types during this period. Future work in this area should fully explore the influence of screen time on food choice and nutritional intake of children.

\section{P511 PARENTAL KNOWLEDGE OF PHYSICAL ACTIVITY GUIDELINES AND LEVELS OF PHYSICAL ACTIVITY IN CHILDREN}

Katriona Fox, Niall Dalton*, Alex Boldy, Madalene Khalil, Paul Scully, Clodagh O'Gorman. University Hospital Limerick, Limerick, Ireland

\subsection{6/archdischild-2019-epa.847}

Introduction Childhood obesity is a risk factor for developing metabolic syndromes, with these patients five times as likely to develop type 2 diabetes compared to those without metabolic syndromes. Significant contributors to obesity include decreased physical activity, poor diet, and sedentary behaviours, especially television viewing. Current guidelines recommend no more than 2-hours non-educational screen-time per day.

Aims Examining parental knowledge regarding exercise guidelines, the portrayal of exercise on television and to ascertain self-reporting of physical activity and any relevant barriers.

Methods Cross-sectional survey on parents of children aged 416 years old, presenting to University Hospital Limerick, October-April,2018. Surveys regarding television viewing and perceptions of television portrayal of exercise. Data analysed on SPSS.

Results Sixty parents completed the surveys and the majority of were aware that 60 minutes is the recommended guideline (50\%), despite a wide answer range (20-240 min). Most parents believed dancing was the most common exercise depicted on television (40\%). 60\% of children met activity guidelines during weekdays, with this increasing to $75 \%$ at weekends. Two-thirds of parents surveyed were not concerned regarding their child's activity levels. Commonly reported barriers to exercise were time involved and cost.

Conclusions Results showed parents were aware of physical activity guidelines and of exercise portrayal on television. Selfreporting indicated two-thirds of children were meeting minimum recommended activity guidelines during the week. Results show that despite parental knowledge regarding guidelines, many children do not meet recommendations, which is associated with increased sedentary television viewing. Future work in this area should fully explore mechanisms underpinning reduced activity and relevant interventions.

\section{P512 CHILDREN AND HEALTHY EATING HOW DO THEY UNDERSTAND IT}

Khajik yaqob*. 'Zakho Genral Hospital, Kurdistan Pediatric Society, DUHOK, Iraq

\subsection{6/archdischild-2019-epa.848}

Background Globally, 10\% of all children and 43 million children under 5 years are either overweight or obese (Livingstone, 2014).According to Livingstone (2014), childhood obesity is one of the serious public health challenges in the $21^{\text {st }}$ century because of its impacts on childhood mental and physical health. Also, the most serious complication of childhood obesity is type 2 diabetes which might result in obese middle age adults and early dementia. Once childhood obesity is established, obesity is notoriously difficult to treat.

Livingstone (2014) stated that approximately $30 \%$ of obese children and $70 \%$ of obese adolescents will go on to become obese adults. Girls are more likely to be affected than boys. The longer a child remains obese beyond 3 years old the more likely that obesity will persist into adulthood. Possibly by 2020 , worldwide, 9\% of all preschool children (approximately 60 million children) will be obese; if no significant intervention is done.

Objective This research study was designed to explore children's (aged 9-10) beliefs about healthy eating and what they manage to eat healthily.

Design This research was exploratory to the way that two different groups of children conceptualized healthy eating to compare between them. One was at a primary school cohort and another at a local Church group. The same questionnaire comprised of 14 questions was administered to children in both cohorts with the twenty-six year 9 and 10 participants to explore how they perceived healthy eating. Total number of children (aged 9-10) was 26, 19 at primary school group and 7 at local Church cohort. Both cohorts were from the same ethnicity (whitish-British), age, gender and low-middle socioeconomic states and different level of education of parents.

Results Although children at primary school age group were more likely to make healthy food choices than those of the local Church group, $(77.3 \%$ vs. $47.1 \%) 71 \%$ favour to eat unhealthy foods. Also, $26.3 \%$ of children at the primary school group as compared to $28.5 \%$ of those in the local Church group thought that pasta is made from cheese and $14.2 \%$ of children at local Church cohort believed that pasta is made from meat. $10.5 \%$ of children at primary school cohort perceived that egg is made from Cow and $5.2 \%$ believed that Crisps is made from plastics.100\% of children in the local Church group as compared to $36.8 \%$ of those at primary school cohort had knowledge of healthy eating from their parents.

\section{P513 PREVALENCE OF HOSPITAL-ACQUIRED MALNUTRITION IN CHILDREN AT A TUNISIAN TERTIARY REFERRAL HOSPITAL}

${ }^{1,2}$ Rania Ben Rabeh* ${ }^{1,2}$ Amani Ahmed, ${ }^{1,2}$ Sonia Mazigh Mrad, 1,2Salem Yahyaoui,

${ }^{1,2}$ Samir Boukthir. 'BECHIR HAMZA Children's hospital, Tunis, Tunisia; ' ${ }^{2}$ University Tunis El Manar, Faculty of medicine, Tunis, Tunisia

10.1136/archdischild-2019-epa.849

Introduction Hospital-acquired malnutrition (HAM) occurs as a result of reduction in food intake and an increased calorie requirement resulting from high catabolic state induced by the disease.The prevalence of HAM is underestimated, mainly in the pediatric population.

Objectives This study aimed to investigate the prevalence and risk factors of hospital-acquired malnutrition in Tunisian children.

Methods Prospective, descriptive and analytical study, including all children over 28 days of age hospitalized for at least 48 hours in the pediatric department ' $\mathrm{C}$ ' of BECHIR HAMZA Children's Hospital from April 2018 to September 2018, was conducted. Children with dehydration or edematous syndrome were excluded from the study. The prevalence of HAM was estimated by a $25 \%$ decrease in $\mathrm{z}$-score BMI (body mass 